\title{
THE LACRIMAL STRIP AND THE PRECORNEAL FILM IN CASES OF SJÖGREN'S SYNDROME
}

\author{
BY \\ M. KLEIN \\ LONDON
}

WoLFF has recently suggested that the precorneal film has a triple structure, consisting of a deep mucoid layer, an intermediate lacrimal watery layer, and an oily layer which is very thin (probably not more than of monomolecular thickness), and which floats on the surface of the lacrimal layer. ${ }^{1,2}$ This composite film is the product of different glands and of a mechanism to maintain it. The mucous layer derives from the goblet cells of the conjunctiva, the watery layer from the main and accessory lacrimal glands, and the oily layer from the tarsal glands. The precorneal film is maintained by the following mechanism : Whenever the eye is closed the palpebral conjunctiva comes into direct contact with the cornea, and the mucus from the goblet cells is spread over its surface. The lacrimal layer is responsible for the brightness of the corneal surface, and being completely transparent normally it cannot be seen, but after the instillation of fluorescein it shows up clearly even to the naked eye. An accumulation of this watery layer, the marginal strips, can be easily seen in the gutter formed by the lid margins touching the globe. With every descent of the lid this lacrimal strip replenishes and maintains the watery film. Apart from these anatomical and mechanical factors the relatively high protein content of the tears contributes to the evenness and stability of the lacrimal layer. The oily film can best be seen by the slit-lamp, the beam being directed on the free lid margin and the cornea illuminated by the reflected light. ${ }^{3}$ Sometimes one can see the oily layer even with the naked eye as coloured rings, or as a fine membrane with polychromatic lustre.

It was of interest to observe the lacrimal strip and the precorneal film in several cases of keratoconjunctivitis sicca. Sjögren described how the conjunctiva and cornea lose their brightness, although as a rule they do not look dry. Though in all our observed cases Schirmer's test indicated very marked reduction in, or almost absence of lactimal secretion, the marginal strips of tear fluid were present in all cases. The precorneal film lacked the easy-flowing flexible appearance of the normal film and was rather viscous. The oily superficial layer was also present.

Though we are dealing with keratocohjunctivitis sicca, the

* Received for publication, September 13, 1948. 
marginal strips of tear fluid and the precorneal film are present, a point which so far as I am aware has not been made. Moreover the precorneal film seems to be composed of the usual three elements, but the mucoid component apparently predominates over the lacrimal film. Whether this is due to diminished lacrimal secretion alone, or the composition of the tear fluid is altered as well, needs further investigation. According to Frederick Ridley the protein content of the tears is reduced in cases of Sjögren's syndrome and in xerosis (personal communication). This may be significant, as the surface tension of the tears is influenced by the protein content, and with it the quality of the precorneal film.

My thanks, are due to Mr. Eugene Wolff in whose clinic at the Royal Westminster Eye Hospital these observations were carried out, for his interest and helpful suggestions.

\title{
REFERENCES
}

1. Wolff, Eugene (1948.) - The Anatomy of the Eye and Orbit, 3rd Ed. London.

2. - (1946).-Trans. Ophthal. Soc., U.K. 64, 291.

3. - (1946).-Bull. Soc. belge. d'Ophtal., 84, 125.

\section{THE RELATION BETWEEN PERIPHERAL} RETINAL CYSTS AND DIALYSES*

\author{
BY \\ Sir Stewart DUKe-Elder
}

LONDON

THE simultaneous occurrence of cysts at the periphery of the retina and dialyses has been remarked on several occasions, and although a close relation between the two has been suggested, I have been unable to find definite proof that a dialysis may develop from the bursting of a cyst. The following case, which by a fortunate chance illustrated this sequence, is therefore of importance.

A healthy adult male, aged 44 years, was first seen on April 16, 1946 ; distant vision was normal and his only complaint was of presbyopia. In the left eye, however, a typical retinal cyst, approximately $2 \times 1$ disc diam., occupied the extreme periphery in the usual position, down and out at about 5 o'clock. He was seen three months later, when the cyst showed no observable change. After a further three months, however, the cyst had enlarged by about one-third and, although he had no subjective symptoms, in view of the fact that he proposed to go abroad for some years, an operation was arranged, the intention being to puncture the cyst by

- Received for publication, February 14, 1949. 